\title{
AS AÇÕES DE FORMAÇÃO PROFISSIONAL DO SERVIÇO NACIONAL DE APRENDIZAGEM DO COOPERATIVISMO (SESCOOP/RN) NOS TERRITÓRIOS DO RIO GRANDE DO NORTE
}

\author{
THE PROFESSIONAL TRAINING ACTIONS OF THE NATIONAL \\ COOPERATIVE LEARNING SERVICE (SESCOOP/RN) IN THE \\ TERRITORIES OF RIO GRANDE DO NORTE STATE, BRAZIL
}

\author{
Emanoel Márcio Nunes ${ }^{1}$ \\ https://orcid.org/0000-0002-9045-887X \\ Vívian Menezes da Silva ${ }^{2}$ \\ https://orcid.org/0000-0003-2177-9271
}

Submissão: 31/08/2021 / Aceito: 04/11/2021 / Publicado: 23/11/2021.

\begin{abstract}
Resumo
O objetivo é analisar a importância e o alcance das ações de formação profissional do Serviço Nacional de Aprendizagem do Cooperativismo no Rio Grande do Norte (SESCOOP/RN) nos territórios do Rio Grande do Norte. Para isso partiu-se da discussão sobre Capital Humano e Cooperativismo, e sendo utilizado o método Estudo de Caso. A pesquisa caracteriza-se como bibliográfica e documental e a técnica de pesquisa foi a descritivo-exploratória, tendo sido os dados coletados e extraídos junto ao SESCOOP/RN. Observou-se que as ações da entidade se concentram nos territórios considerados mais dinâmicos do estado, onde as atividades econômicas relacionadas com o cooperativismo acontecem em maior proporção. Por fim, a pesquisa aponta ainda pouco alcance das ações do SESCOOP-RN, e sugere a necessidade de uma maior ampliação e expansão das atividades cooperativistas nos territórios do Rio Grande do Norte.
\end{abstract}

Palavras-chave: Sistema "S”. Educação. Formação Profissional. Capital Humano.

\begin{abstract}
The objective is to analyze the importance and scope of professional training actions of the National Service for Learning Cooperatives in Rio Grande do Norte state (SESCOOP/RN) in the territories of Rio Grande do Norte state, Brazil. For this, we started from the discussion about Human Capital and Cooperatives, and using the Case Study method. The research is characterized as bibliographic and documentary and the research technique was descriptive-exploratory, with data collected and extracted from SESCOOP/RN. It was observed that the entity's actions are concentrated in territories considered the most dynamic in the state, where economic activities related to cooperativism take place in

\footnotetext{
${ }^{1}$ Doutor em Desenvolvimento Rural pela Universidade Federal do Rio Grande do Sul (PGDR/UFRGS). Professor da graduação e do Programa de Pós-Graduação em Economia (PPE/UERN) da Faculdade de Ciências Econômicas da Universidade do Estado do Rio Grande do Norte (FACEM/UERN). E-mail: emanoelnunes@uern.br

${ }^{2}$ Mestre pelo Programa de Pós-Graduação em Planejamento e Dinâmicas Territoriais no Semiárido da Universidade do Estado do Rio Grande do Norte (PLANDITES/UERN). E-mail: menezesvivian123@gmail.com
} 
greater proportion. Finally, the research still points out that SESCOOP-RN's actions have little scope, and suggests the need for a greater expansion and expansion of cooperative activities in the territories of Rio Grande do Norte state.

Keywords: "S" System. Education. Professional Qualification. Human Capital.

\section{INTRODUÇÃO}

As atividades cooperativistas foram iniciadas na Inglaterra no século XIX, como uma iniciativa que sinalizava para a diminuição dos problemas socioeconômicos vividos por trabalhadores da indústria no período da revolução industrial inglesa, no momento em que notaram a possibilidade de vantagem econômica fazendo com que os seus baixos salários rendessem um pouco mais. A estratégia foi colocada em prática e ampliada quando famílias reunidas em uma cooperativa passaram a obter vantagem econômica por se beneficiarem da escala possibilitada, sempre que compravam alimentos, vestuários e outros itens de consumo direto a preços mais baixos. A força da ação coletiva levou famílias de trabalhadores à um processo de relativo aumento dos baixos padrões de consumo resultantes das precárias condições de trabalho em que estes se encontravam e que reproduziam baixos índices salariais oriundos de jornadas exaustivas de trabalho. Inicialmente, com um grupo de 28 trabalhadores que possuíam os mesmos objetivos, fundou-se a Sociedade dos Probos Pioneiros de Rochdale, em 1844.

Alguns princípios são a base norteadora da cultura cooperativista, sendo eles: liberdade e voluntariedade da adesão; administração democrática; intercooperação; autonomia; interesse pela comunidade; promoção da educação; distribuição adequada dos resultados. Desde o seu advento, a educação e a qualificação se tornaram um dos principais fatores que fundamentam os preceitos cooperativistas, considerando que a cooperativa é constituída por pessoas, e que os investimentos em capital humano devem ser realizados para que se alcancem níveis crescentes de produtividade, que haja o pleno desenvolvimento de competências e que tudo isso se traduza em elevação dos níveis de renda.

Como abordado por Schultz (1973), sem os investimentos em capital humano, haveria apenas o trabalho rude, manual e a pobreza. Diante disso, o Serviço Nacional do Cooperativismo (SESCOOP/RN), instituído em 1998, se configura numa entidade de caráter privado, e atua como o braço educacional responsável pela formação e qualificação profissional dos cooperados. A partir de metodologias específicas, o SESCOOP/RN oferta cursos de Formação Inicial ou Continuada (FIC), Educação Profissional Tecnológica Técnica e de Nível Médio e Educação Profissional Tecnológica de Graduação e de PósGraduação para os cooperados, gestores e funcionários das cooperativas. O SESCOOP/RN compõe o chamado Sistema "S" e é mantido por uma alíquota que incide sobre a folha de pagamento das cooperativas parceiras dos atuais sete ramos de atividade (agropecuário, consumo, crédito, infraestrutura, trabalho e produção de bens e serviços, saúde e transporte) e integra a Organização das Cooperativas do Brasil (OCB).

Considerando a importância das capacitações no âmbito das cooperativas, uma vez que, contribuem com o desenvolvimento pessoal e profissional dos seus cooperados a questão que se coloca é: qual o alcance das ações de qualificação profissional do Serviço Nacional de Aprendizagem do Cooperativismo (SESCOOP-RN), no sentido de contribuir com a qualificação do seu capital humano, ou seja, os cooperados, gestores e funcionários das cooperativas, e, consequentemente, para a dinamização socioeconômica dos territórios do Rio Grande do Norte? Como pressuposto, cabe ressaltar que o SESCOOP-RN possui 
uma atuação de qualificação em vários municípios potiguares, e o seu alcance acontece a partir do seu quadro de consultores que, por meio de metodologias específicas, se propõe a suprir e/ou amenizar as necessidades das cooperativas que costumam desempenhar suas atividades a partir dos seus ramos.

Neste sentido, o objetivo deste artigo é analisar a importância e contribuição do Serviço Nacional de Aprendizagem do Cooperativismo (SESCOOP-RN), considerando as demandas dos municípios que buscam na formação profissional dos cooperados, gestores e funcionários das cooperativas do estado do Rio Grande do Norte.

O trabalho baseou-se no estudo de caso, partindo da pesquisa bibliográfica e documental, caracterizando-se como descritivo-exploratório. Os dados foram coletados junto ao SESCOOP/RN no ano de 2021, o local da pesquisa foram os dez territórios rurais do Rio Grande do Norte da Secretaria de Desenvolvimento Territorial (SDT) do extinto Ministério do Desenvolvimento Agrários e conclui-se que as ações da instituição tendem a se darem de forma mais concentrada onde as suas unidades regionais estão localizadas, como também, nos territórios considerados mais dinâmicos do estado e onde as atividades econômicas se dão em maior intensidade.

\section{REFERENCIAL TEÓRICO}

\section{A Perspectiva do Capital Humano}

A Teoria do Capital Humano introduziu a heterogeneidade no que concerne à mão de-obra, centrando-se na educação para a aquisição de competências e estabelecendo assim uma correlação positiva entre o nível de educação e o nível de produtividade. Esta abordagem trouxe uma maior preocupação no que diz respeito a problemas de inadequação de competências (LOURENÇO, 2015, p. 7).

Schultz (1973, p.53), classifica o Capital Humano como sendo sua principal característica advinda do homem:

\footnotetext{
É humano porquanto se acha configurado no homem, e é capital porque é uma fonte de satisfações futuras, ou de futuros rendimentos, ou ambas as coisas. Onde os homens sejam pessoas livres, o capital humano não é um ativo negociável, no sentido de que possa ser vendido. Pode, sem dúvida, ser adquirido, não como um elemento de ativo que se adquire no mercado, mas por intermédio de um investimento no próprio indivíduo. Segue-se que nenhuma pessoa pode separar-se a si mesma do Capital Humano que possui. Tem de acompanhar, sempre, o seu Capital Humano, quer o sirva na produção ou no consumo.
}

Para Cabral, Silva e Silva (2016) a relação entre capital humano e desenvolvimento econômico aconteceria da seguinte forma: um acréscimo marginal de escolaridade corresponderia a um acréscimo marginal de produtividade; a renda é função da educação. Sendo assim, se torna um eficiente instrumento de distribuição de renda e de equalização social. O cálculo da rentabilidade estaria vinculado à diferença da renda provável das pessoas que se escolarizaram e das outras que não o fizeram (CABRAL, SILVA e SILVA, 2016, p.37).

Para Lourenço (2015, p.4), o Capital Humano se constitui em um dos principais fatores no alcance do desenvolvimento econômico de determinados países e as disparidades 
que ocorrem entre algumas nações pelo fato de algumas serem mais evoluídas do que outras possui como um dos principais fatores as disparidades educacionais.

Para Nunes, Silva e Sá (2020), o baixo índice educacional representa um dos fatores determinantes de baixos níveis de produtividade e da renda nas populações de regiões menos desenvolvidas, se tornando uma séria limitação para iniciar processos de desenvolvimento. Assim, uma política educativa mais eficiente dependerá indubitavelmente das razões que conduzem a educação e a formação a promover o crescimento, bem como dos mecanismos e processos através dos quais a educação se traduz no desenvolvimento e aumento da produtividade e, consequentemente, da renda (LOURENÇO, 2015).

Para Mincer (1958) além do capital físico, havia outro fator que deveria ser considerado no processo de crescimento econômico e que incorporava os fatores de produção. Somente o capital físico era insuficiente para explicar a elevação do crescimento econômico e da produtividade que ocorria em alguns países e regiões. Sendo assim, o autor concluiu que os rendimentos pessoais estavam relacionados diretamente com os investimentos em capital humano, dos quais impactavam na produtividade e no crescimento econômico.

Schultz (1973) aborda o efeito da escolaridade sobre os rendimentos. Os indivíduos investem em capacitações particulares (médicos, engenheiros, advogados, etc.), visando retornos futuros. Segundo o autor, a educação pode ser vista como consumo, por trazer bem-estar, mas não retorno imediato ou como rendimento, onde se transformará em retorno futuro. A educação também pode fazer progredir as capacitações das pessoas e, desta forma, incrementar os seus futuros rendimentos (SCHULTZ, 1973).

Ainda para o autor a educação tornou-se fator determinante do crescimento econômico, pois esse último seria impossível se o capital humano fosse composto por analfabetos:

\begin{abstract}
A educação tornou-se uma fonte de maior importância para o crescimento econômico ao conquistar a abundância que terá de haver, ao desenvolver-se uma agricultura e uma indústria modernas. Simplesmente não seria possível ter-se uma tal abundância se as pessoas fossem predominantemente analfabetas ou sem qualquer capacitação técnica. A educação, por conseguinte, além do acréscimo em apresentar altos valores culturais, é efetivamente também um investimento nas pessoas, à medida que afeiçoa as suas capacitações e, portanto, aumenta os futuros rendimentos a serem auferidos pelos indivíduos (SCHULT, 1973, p.60).
\end{abstract}

O capital humano se encaixa bem numa função de produção, contribuindo com a produtividade, dando-nos a confiança de que, o trabalho com carga educacional pesa na produção final. $\mathrm{O}$ investimento em capital humano concentra-se na aquisição de conhecimentos e no próprio indivíduo para o alcance produtivo.

\title{
Cooperativismo: Breve Histórico
}

A literatura argumenta que as discussões em torno do cooperativismo surgiram a partir da revolução industrial e do movimento operário do século XIX, em um cenário de dificuldades, momento do qual os problemas socioeconômicos emergiram com maior intensidade e as disparidades entre as condições de trabalho e a substituição do homem pela máquina desencadearam problemas sociais e econômicos a sociedade. 
Há autores que abordam o ato de cooperar como inerente ao próprio ser humano. De acordo com Sales (2010, p.24):

\begin{abstract}
O cooperativismo é uma forma de somar capacidade dentro de um mundo de concorrência. É uma forma de preservar a força econômica e de vida dos indivíduos de um mesmo padrão e tipo, com objetivos comuns e com as mesmas dificuldades. A cooperativa quase sempre surge em momentos de dificuldades e da consciência de fragilidade do homem dentro do mundo em que atua.
\end{abstract}

As cooperativas surgiram como um meio de intervir nas condições de vida de trabalhadores que se encontravam a margem das condições de trabalho, levando-os à construção de estratégias que se traduzissem em alguma vantagem econômica. De acordo com Costa (2007), a primeira cooperativa que alcançou êxito foi a de Rochdale com Sociedade dos Probos Pioneiros de Rochdale, na Inglaterra, inicialmente com 28 operários do setor têxtil em 1844, como uma cooperativa de consumo alcançando depois de dez anos 5.300 associados. Como nos mostra a história, foi em um ambiente de dificuldade financeira e de condições de vida precárias que as ideias cooperativistas se firmaram e os avanços das práticas industriais e diminuição da atividade artesanal, inicia-se a exploração da mão-de-obra, o cooperativismo surge como forma de amenizar os traumas econômicos e sociais que estas transformações submeteram o homem da época (SALES, 2010, p.29).

Por volta de 1840, para superar as dificuldades trazidas pelo capitalismo surgiu o cooperativismo na Inglaterra, com os Pioneiros de Rochdale. Este grupo de pioneiros era formado por tecelões que laboravam mais de 16 horas por dia, tinham condições precárias de moradia e alimentação e estavam amedrontados com a possibilidade de desemprego trazida pelo surgimento da máquina a vapor. Diante dessas dificuldades e inspirados pelos ideais do socialista utópico Robert Owen fundaram a primeira cooperativa de que se tem registro e que tinha por objetivo o suprimento de suas necessidades básicas a um custo reduzido. Ancoradas pelo êxito dos pioneiros, logo surgiram mais de 500 cooperativas na Inglaterra (MARCHIORO, PONTES e SILVA, 2017, p.4).

Marchioro, Pontes e Silva (2017) abordam que em regiões que possuem cooperativas os Índices de Desenvolvimento Humano (IDH) da população são superiores as que não as possuem, tornando-se um dos fatores propulsores do desenvolvimento regional de determinados países. E esses fatores propulsores constroem ao longo do tempo, conforme Nunes, Gondim e Silva (2019), uma identidade cooperativista visando o aperfeiçoamento da gestão para a dinamização econômica por meio das cooperativas. Essa estratégia tende a impulsionar cada vez mais processos de reestruturação produtiva em dinâmicas de desenvolvimento no interior de determinados territórios, contribuindo para a consolidação de uma cultura cooperativista e de um ambiente com maiores níveis de cooperação.

Os chamados princípios universais que norteiam a cultura cooperativista, segundo Namorado (2012), são sete: liberdade e voluntariedade da adesão; administração democrática; intercooperação; autonomia; interesse pela comunidade; promoção da educação; distribuição adequada dos resultados. Entre os valores, destacam-se a igualdade, a solidariedade, a honestidade e o altruísmo.

Para Nunes, Silva e Sá (2020), a educação é considerada um dos eixos norteadores no âmbito do desenvolvimento cooperativista, pois é introduzida integrada com a cultura numa tentativa de criar coesão e manter a unidade com a prática contínua e intensa de 
cooperação. Segundo Ploeg (2018), a educação contribui para o aperfeiçoamento das estratégias de cooperação, sendo fundamental para aproveitar as habilidades e ampliar os excedentes gerados por rendimentos crescentes que resultam dos níveis cada vez maiores e melhores de produtividade. A educação desempenha o seu papel ao longo do tempo, considerando especialmente as relações de proximidade do ambiente das comunidades, como aborda Ferreira e Sousa (2017, p.778):

\begin{abstract}
É interessante mencionar que os Pioneiros de Rochdale dispensavam substancial atenção, de um modo geral, às iniciativas de educação dos associados e da comunidade cooperativista, sendo a educação um princípio cooperativista, enaltecido e respeitado em seu meio. Dedicavam esforços, em grande medida, à educação de seus membros, por acreditarem ser essencial que estivessem bem informados sobre sua realidade.
\end{abstract}

Nesse sentindo, tem-se no estado do Rio Grande do Norte o SESCOOP/RN Serviço Nacional de Aprendizagem Cooperativista, entidade de caráter privado que compõe o chamado Sistema "S", responsável pela formação profissional dos cooperados, empregados e cooperativas, instituída em 1998 no país compondo o Sistema OCB Organização das Cooperativas do Brasil. Atua na qualificação profissional dos cooperados disponibilizando cursos de Formação Inicial e Continuada (FIC), Educação Profissional Técnica e de Nível Médio e Tecnológica de Graduação e Pós-Graduação. O direcionamento da formação busca, segundo Nunes, Cruz e Silva (2020), uma associação cada vez mais interativa com sistemas de acompanhamento técnico para as atividades cooperativistas, no sentido de garantir níveis melhores de eficiência e, consequentemente, o êxito esperado. $\mathrm{O}$ SESCOOP/RN é uma instituição paraestatal, considerando que atua lado a lado do estado em prol de atividades de interesse público, e é mantida por uma alíquota que incide sobre a folha de pagamento das cooperativas parceiras.

\footnotetext{
Sendo a mais nova instituição do chamado Sistema "S", o Sescoop foi criado com o intuito de investir continuamente nos cooperados, dirigentes e empregados, ajudando a profissionalizar a gestão das cooperativas e viabilizar a operacionalização do monitoramento, supervisão, auditoria e controle destas. Tem ainda como objetivo assessorar o governo federal em assuntos de formação profissional e gestão cooperativista e de contribuir para a formulação de políticas adequadas à criação de postos de trabalho e geração de renda (FERREIRA e SOUSA, 2018, p.776)
}

A entidade é responsável por ofertar atividades e ações de formação profissional que contribuam e potencialize o desenvolvimento e a gestão dos empreendimentos cooperativos. A educação cooperativista é reconhecidamente um dos pilares de sustentação do desenvolvimento cooperativo, formando parte tanto dos princípios, como das necessidades explícitas dessas organizações (FERREIRA e SOUSA, 2018, p778).

\title{
METODOLOGIA
}

\section{Área de Estudo}

O trabalho teve como local de estudo os dez (10) territórios rurais, em atendimento ao recorte territorial da Política Nacional de Desenvolvimento Territorial coordenada pela Secretaria de Desenvolvimento Territorial (SDT), do então extinto Ministério do 
Desenvolvimento Agrário (MDA) que, conforme Nunes, Tôrres, Silva, Sá e Godeiro (2015), são os a seguir: Açu-Mossoró, Terra dos Potiguaras, Seridó, Potengi, Agreste Litoral Sul, Mato Grande, Alto Oeste Potiguar, Sertão Central Cabugi e Litoral Norte, Trairi e Sertão do Apodi. O estado do Rio Grande do Norte é composto por 167 municípios com uma área territorial de $8.510 .345 .538 \mathrm{~km}^{2}$ e com uma população de aproximadamente 213.317.639 pessoas (IBGE, 2021).

Figura 1 - Territórios Rurais do Rio Grande do Norte.

\section{RIO GRANDE DO NORTE}

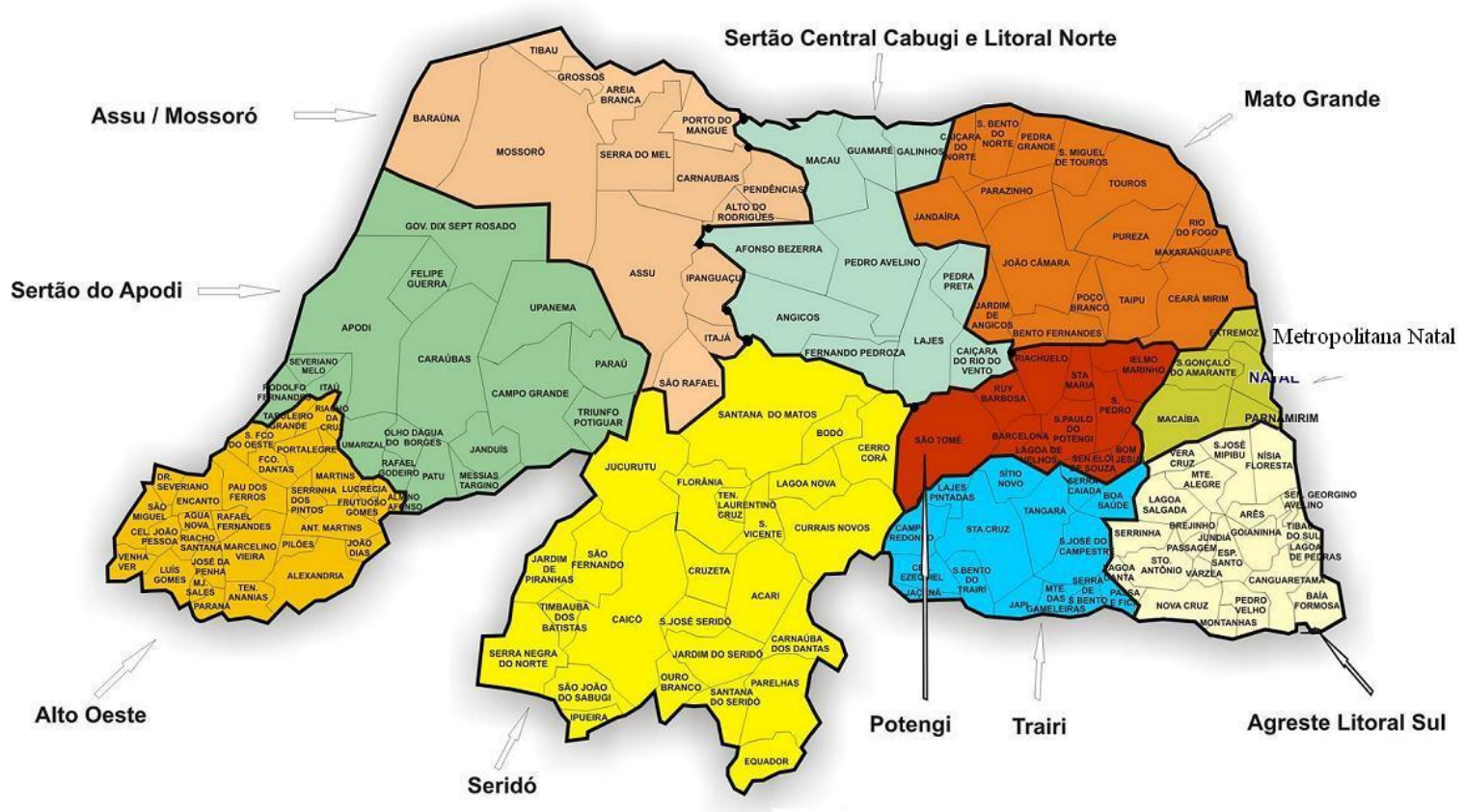

Fonte: PTDRS (2010).

O território Açu-Mossoró é composto por quatorze municípios (14), o território Terra dos Potiguaras é composto por cinco (05) municípios, o território Potengi é composto por onze municípios (11), o território Trairi é composto por quinze municípios (15), o território Alto Oeste é composto por trinta (30) municípios, o território Sertão do Apodi é composto por dezessete (17) municípios, o território Mato Grande é composto por dezesseis (16) municípios, o território Seridó é composto por vinte e cinco municípios (25), o território Agreste Litoral Sul é composto por vinte e quatro municípios (24), e o território Sertão Central Cabugi e Litoral Norte é composto por dez (10), municípios. A entidade do SESCOOP/RN possui duas unidades regionais localizadas no estado do Rio Grande do Norte, uma no território Terra dos Potiguaras e uma no território Seridó.

Para se alcançar o objetivo proposto da presente pesquisa, a saber: verificar a presença das ações de formação profissional do SESCOOP/RN nos territórios do Rio Grande do Norte, o estudo partiu de uma caracterização de pesquisa bibliográfica e documental, considerando que nenhuma pesquisa se inicia do zero. Para Gil (2008), 
enquanto a pesquisa bibliográfica utiliza-se da contribuição de vários autores sobre dado assunto ou temática, a pesquisa documental utiliza-se de materiais dos quais ainda não receberam tratamento.

O presente estudo classifica-se em dos níveis: como exploratória, pois estas possuem o objetivo de proporcionar visão geral e/ou aproximativa sobre determinado assunto e é utilizado principalmente quando o tema abordado é pouco explorado, como também descritiva, pois objetivou-se descrever acerca de um grupo e/ou população específica e sua relação entre variáveis (GIL, 2008).

Partindo também de uma abordagem de pesquisa mista, onde há a mobilização tanto de dados qualitativos quanto quantitativos, Creswell (2007) afirma que, uma pesquisa é considerada mista quando há a utilização de informações associadas as duas formas de dados, dessa forma, possui como objetivo reunir dados quali-quantitativos em um único estudo.

Por fim, o método utilizado foi o estudo de caso, que para Fachin (2005), esse método leva em consideração, principalmente, a compreensão como um todo, do assunto investigado. $\mathrm{E}$ os dados utilizados foram extraídos junto a unidade regional do SESCOOP/RN localizada no estado, referente aos anos de 2018, 2019 e 2020. Quanto ao tratamento, tabulação e análise dos mesmos, foram realizados no software word e excell 2013.

\section{RESULTADOS E DISCUSSÃO}

De acordo com dados do Serviço Nacional de Aprendizagem do Cooperativismo (SESCOOP-RN), o estado do Rio Grande do Norte apresentava no ano de 2018 um arranjo formado por 158 cooperativas, 52.507 cooperados e 2.178 empregados, ainda nos seus 13 ramos, conforme mostra a tabela1. 
Tabela 1: Arranjo do cooperativismo do Rio Grande do Norte constituído pelos ramos, cooperativas cooperados e empregados

\begin{tabular}{c|c|c|c|c|c|c|c|c|c}
\hline \multirow{2}{*}{ RAMOS } & \multicolumn{2}{|c|}{ COOPERATIVAS } & \multicolumn{2}{c|}{ COOPERADOS } & \multicolumn{2}{c}{ EMPREGADOS } \\
\cline { 2 - 10 } & $\mathbf{2 0 1 7}$ & $\mathbf{2 0 1 8}$ & $\begin{array}{c}\text { Var } \\
(\boldsymbol{\%})\end{array}$ & $\mathbf{2 0 1 7}$ & $\mathbf{2 0 1 8}$ & $\begin{array}{c}\text { Var } \\
(\boldsymbol{\%})\end{array}$ & $\mathbf{2 0 1 7}$ & $\mathbf{2 0 1 8}$ & $\begin{array}{c}\text { Var } \\
(\boldsymbol{\%})\end{array}$ \\
\hline Agropecuário & 37 & 43 & $16,2 \%$ & 829 & 3.543 & $327,4 \%$ & 12 & 27 & $125,0 \%$ \\
\hline Consumo & 7 & 8 & $14,3 \%$ & 3.822 & 3.953 & $3,4 \%$ & 16 & 1.623 & $\begin{array}{c}10043,8 \\
\%\end{array}$ \\
\hline Crédito & 6 & 6 & $0,0 \%$ & 18.608 & 18.772 & $0,9 \%$ & 155 & 151 & $-2,6 \%$ \\
\hline Educacional & 8 & 8 & $0,0 \%$ & 683 & 1.085 & $58,9 \%$ & 10 & 15 & $50,0 \%$ \\
\hline Especial & 0 & 0 & - & 0 & 0 & - & 0 & 0 & - \\
\hline Habitacional & 4 & 5 & $25,0 \%$ & 6.799 & 6.740 & $-0,9 \%$ & 8 & 94 & $\begin{array}{c}\% \\
\%\end{array}$ \\
\hline Infraestrutura & 9 & 9 & $0,0 \%$ & 16.005 & 26.992 & $68,6 \%$ & 2 & 4 & $100,0 \%$ \\
\hline Mineral & 2 & 2 & $0,0 \%$ & 0 & 20 & - & 0 & 0 & - \\
\hline Produção & 14 & 16 & $14,3 \%$ & 1.179 & 1.160 & $-1,6 \%$ & 13 & 16 & $23,1 \%$ \\
\hline Saúde & 13 & 14 & $7,7 \%$ & 1.250 & 2.779 & $122,3 \%$ & 58 & 1.577 & $\begin{array}{c}2619,0 \\
\%\end{array}$ \\
\hline Trabalho & 19 & 20 & $5,3 \%$ & 510 & 1.015 & $99,0 \%$ & 1 & 11 & $\begin{array}{c}\% \\
\%\end{array}$ \\
\hline Transporte & 24 & 25 & $4,2 \%$ & 1.247 & 2.270 & $82,0 \%$ & 59 & 135 & $128,8 \%$ \\
\hline Turismo e Lazer & 2 & 2 & $0,0 \%$ & 0 & 0 & - & 0 & 0 & - \\
\hline
\end{tabular}

Fonte: SESCOOP-RN, 2020

Esse arranjo constituído pelas cooperativas representa um sistema possuidor de uma significativa importância para a dinâmica econômica e social do Rio Grande do Norte, sendo o principal ambiente de atuação do SESCOOP/RN para as suas ações de qualificação profissional, por meio da oferta de curso de Formação Inicial Continuada (FIC). O SESCOOP/RN é uma entidade de direito privado que compõe o chamado Sistema "S", integrante do sistema OCB - Organização das Cooperativas do Brasil, instituído em 1998, sendo responsável por administrar, organizar e executar atividades de formação profissional direcionadas ao cooperativismo em todo o território nacional. A entidade pauta sua metodologia de ensino no desenvolvimento de competências onde há a mobilização de conhecimentos (saber), habilidades (saber fazer) e atitudes (saber ser), para a ocupação de cargos específicos.

Quando se trata de fortalecer e consolidar as práticas cooperativistas, a contribuição do SESCOOP-RN tem sido a de criar e promover o melhoramento contínuo do ambiente institucional (no nível macro e de coordenação) que afeta diretamente o arranjo institucional das cooperativas (no nível micro e de compartilhamento) em um fluxo que remete a figura 1. 
Figura 1: Fluxo de ações e práticas cooperativista

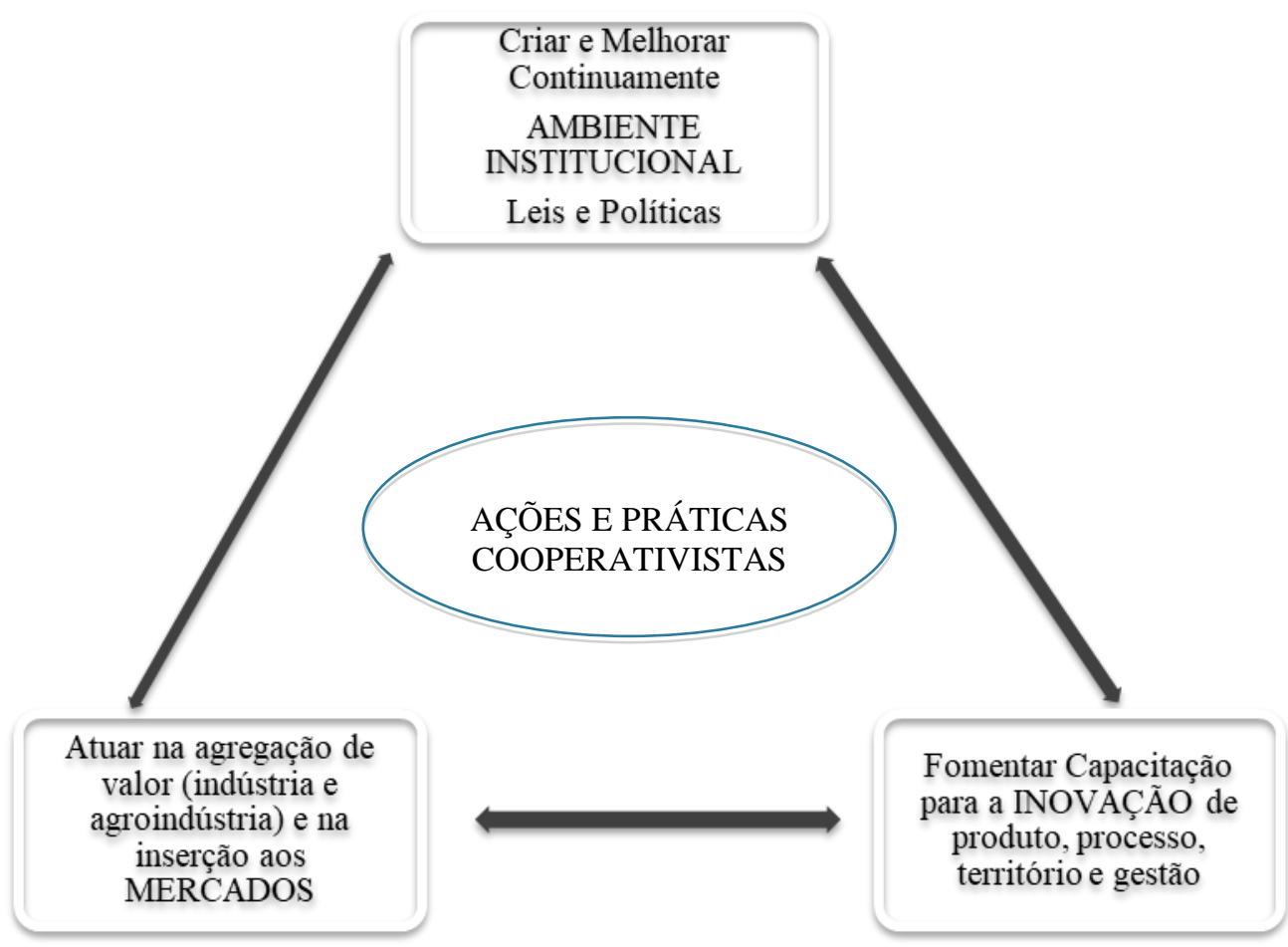

Fonte: Elaboração dos autores (2020).

No período investigado de 2018 a 2020, a entidade ofertou cursos referente a quinze (15) segmentos nos territórios do Rio Grande do Norte, os segmentos tratam-se das áreas das quais a oferta formativa de cursos são disponibilizadas. O Gráfico 1 abaixo mostra as áreas das quais os cursos foram ofertados no período citado. 
Gráfico 1 - Áreas/Segmentos de Atuação

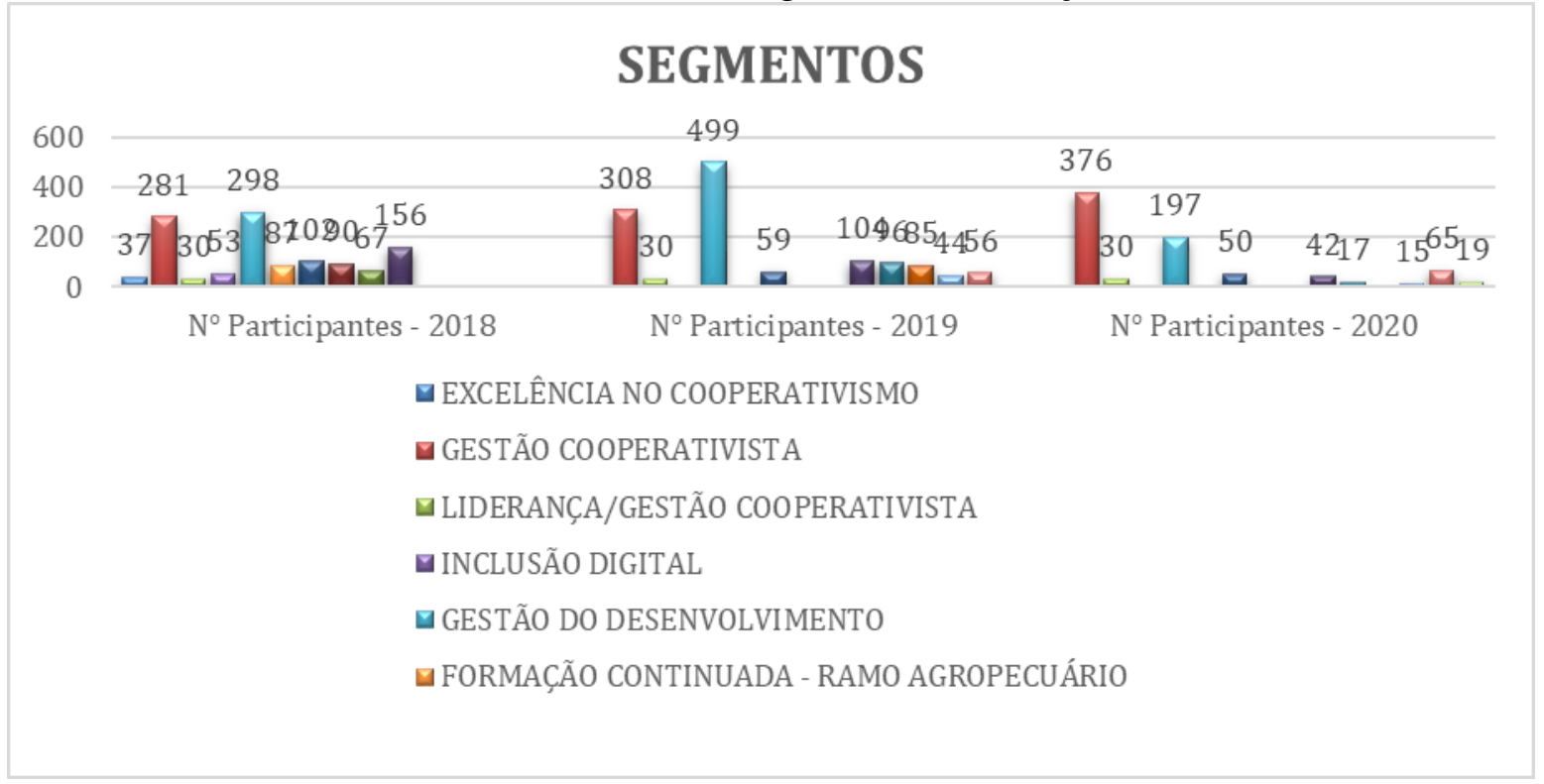

Fonte: SESCOOP/RN (2021).

Foi observado que o segmento com maior número de matriculados foi da área de "Gestão do Desenvolvimento" no ano de 2018 com 298 participantes e no ano de 2019 com 499 participantes. Já no ano de 2020 o segmento com maior oferta de cursos de formação profissional foi "Gestão Cooperativista" com 376 participantes. Ambos os segmentos ofertam cursos voltados a administração e gestão de cooperativas.

No período investigado de 2018 à 2020 o SESCOOP/RN atuou em seis (06) dentre os dez (10) territórios do estado do Rio Grande do Norte, conforme mostra o Gráfico 2.

Gráfico 2 - Número de Matriculados nos Territórios

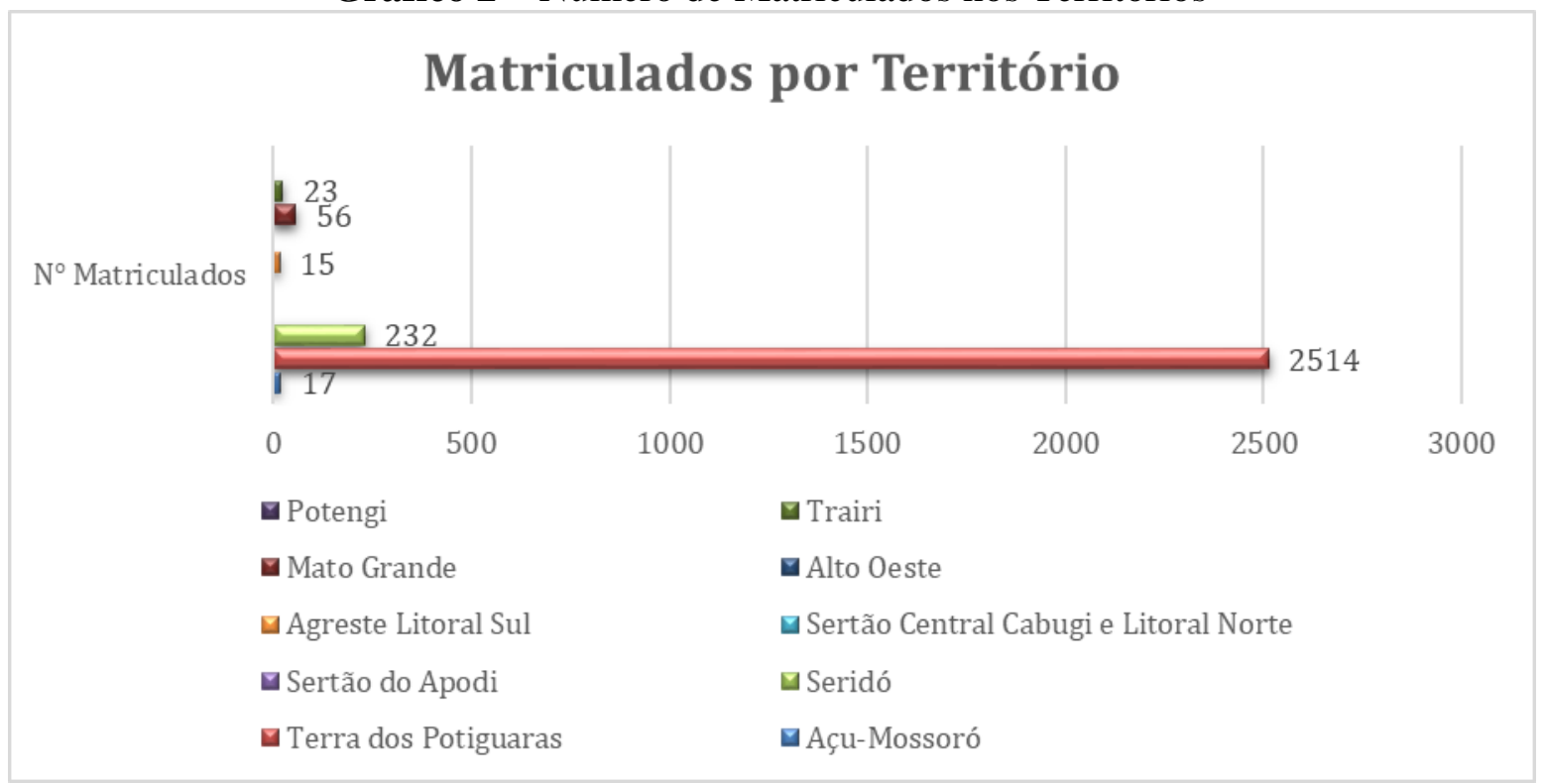

Fonte: SESCOOP/RN (2021). 
Como observado no Gráfico 2, as ofertas de cursos de formação profissional disponibilizados pela instituição concentraram-se no território "Terra dos Potiguaras" com 2.514 matriculados. Em seguida, o território "Seridó" com 232 matriculados e o território "Mato Grande" com 56 matriculados em todo o período investigado. Vale ressaltar que, a instituição tende a localizar-se próximo aos seus parceiros e contribuintes, bem como, nos territórios ou localidades das quais as suas unidades regionais estão localizadas, o que explica a demanda em alguns territórios e não em outros. Essa demanda explica-se também devido ao deslocamento de alunos ou trabalhadores de territórios vizinhos em busca de cursos de qualificação profissional nos territórios considerados mais dinâmicos.

O SESCOOP/RN no período investigado de 2018 a 2020 disponibilizou cursos referentes a quinze (15) segmentos nos territórios do Rio Grande do Norte, os dez (10) cursos com maior número de matriculados consta no gráfico 3 abaixo.

Gráfico 3 - Número de Matriculados por Curso do SESCOOP/RN.

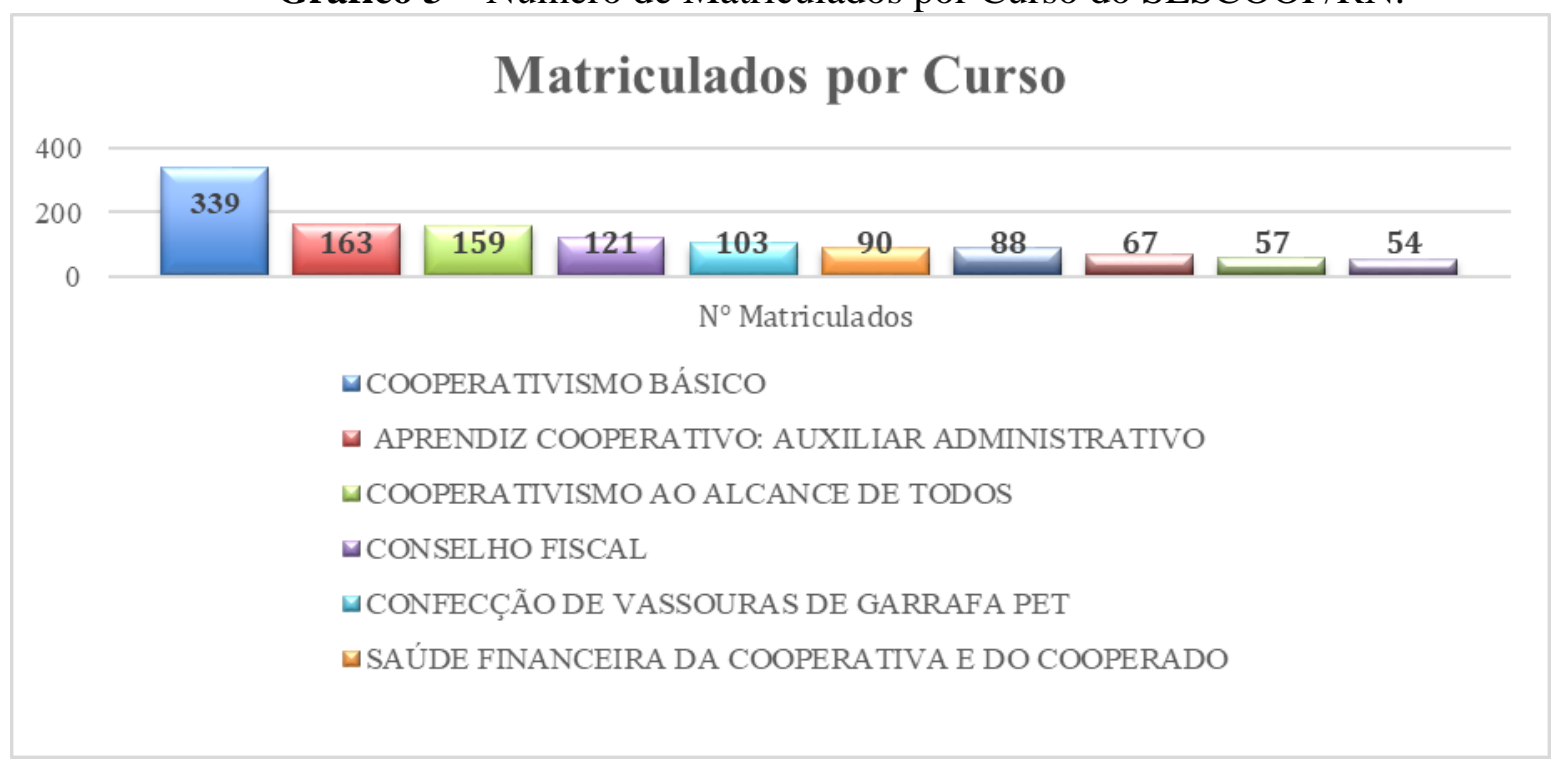

Fonte: SESCOOP/RN (2021).

O curso com maior número de matriculados no período investigado foi "Cooperativismo Básico" com 339 matriculados, em seguida, o curso de "Aprendiz Cooperativo: Auxiliar Administrativo" com 163 matriculados, e o curso "Cooperativismo ao Alcance de Todos" com 159 matriculados. Os três cursos com maior demanda tratam-se de conhecimentos voltados a atividade cooperativista.

As ações de formação profissional do SESCOOP/RN se deram em seis (06) dos dez territórios do estado do Rio Grande do Norte, no período investigado de 2018 à 2020 e em quatorze (14) municípios, conforme mostra Quadro 1 abaixo. 
Quadro 1 - Número de Matriculados por Território e Município.

\begin{tabular}{|c|c|c|c|c|}
\hline TERRITÓRIOS & MUNICÍPIOS & $\begin{array}{c}\mathrm{N}^{\circ} \\
\text { Matriculados } \\
(2018)\end{array}$ & $\begin{array}{c}\mathrm{N}^{\circ} \\
\text { Matriculados } \\
(2019)\end{array}$ & $\begin{array}{c}\mathrm{N}^{\circ} \\
\text { Matriculados } \\
(2020)\end{array}$ \\
\hline \multirow{4}{*}{ Terra dos Potiguaras } & Natal & 765 & 1.118 & 380 \\
\hline & $\begin{array}{c}\text { São Gonçalo do } \\
\text { Amarante }\end{array}$ & 81 & 74 & - \\
\hline & Macaíba & 51 & - & - \\
\hline & Extremoz & - & - & 45 \\
\hline Assú-Mossoró & Assú & 17 & - & - \\
\hline \multirow{4}{*}{ Seridó } & Santana do Seridó & 40 & - & - \\
\hline & São João do Sabugi & 102 & 66 & - \\
\hline & Florânia & 12 & - & - \\
\hline & Parelhas & 12 & - & - \\
\hline Potengi & - & - & - & - \\
\hline Trairi & São Bento do Trairi & 23 & - & - \\
\hline Sertão do Apodi & - & - & - & - \\
\hline $\begin{array}{l}\text { Sertão Central } \\
\text { Cabugi e Litoral } \\
\text { Norte }\end{array}$ & - & - & - & - \\
\hline Alto Oeste & - & - & - & - \\
\hline Agreste Litoral Sul & Monte Alegre & 15 & - & - \\
\hline \multirow{3}{*}{ Mato Grande } & Parazinho & 13 & - & - \\
\hline & São Miguel de Touros & - & 100 & - \\
\hline & Ceará-Mirim & -- & 23 & - \\
\hline
\end{tabular}

Fonte: SESCOOP/RN (2021).

O SESCOOP/RN ofertou cursos no período investigado de 2018 à 2020, conforme Quadro 1, em maior quantidade nos territórios onde há a presença de alguma das suas unidades regionais. A exemplo, o território Terra dos Potiguaras, onde há uma unidade regional no município de Natal, onde a oferta de cursos se deu em maior proporção com 765 matriculados no ano de 2018, 1.118 matriculados no período de 2019 e 380 matriculados no período de 2020. Nesse território, concentrou-se também o maior número de participantes quando da soma total dos municípios. Em seguida, o território Seridó, com maior número de matriculados, território do qual há a presença de uma unidade regional, mais precisamente no município de Caicó, concentrando-se o maior número de matriculados no município de São João do Sabugi, com 102 participantes no ano de 2018 e 66 participantes no ano de 2019. No ano de 2020, as ações da instituição concentraram-se apenas em dois municípios do estado, nos municípios de Natal e Extremoz, o que explicase devido à crise sanitária gerada pelo vírus covid-19, o que impactou a demanda por cursos de qualificação profissional nos territórios.

Observou-se também diante dos dados levantados que as atividades da entidade nos territórios do estado acontecem de forma pouco expressiva, uma vez que, não alcançam os dez (10) territórios e atuando de forma mais concentrada nos territórios considerados mais dinâmicos e onde há a presença de suas unidades regionais. 


\section{CONCLUSÕES}

A pesquisa possibilitou identificar onde há maior ou menor ação de formação profissional nos territórios do Rio Grande do Norte a partir da oferta formativa de cursos do SESCOOP/RN nos territórios do estado. Essas atividades, tendem a se darem de forma mais concentrada nos territórios considerados mais dinâmicos, onde as atividades econômicas relativas a esse segmento acontecem em maior proporção, o que explica a localização das unidades regionais da entidade em alguns territórios e não em outros.

Observou-se que a cultura cooperativista no estado ainda é pouco expressiva a partir dos dados de matriculados por território e municípios. No período investigado de 2018 a 2020, a instituição qualificou 1.241 pessoas, o que aponta para uma maior expansão das atividades cooperativistas nos territórios, uma vez que, essa oferta formativa alcançou apenas seis (6) territórios e quatorze municípios (14).

A importância da integração da educação com a cultura cooperativista, que contribui para processos de dinamização de regiões e territórios como fatores indispensáveis do desenvolvimento. A educação perdura desde a criação da primeira cooperativa, em 1884, e que pode ser identificada também nos dias atuais, como um instrumento indispensável a sua permanência e ao fortalecimento do seu capital humano, especialmente nas relações de proximidade e no ambiente comunitário.

\section{REFERÊNCIAS}

BECKER, Gary S. Human capital: a theoretical and empirical analysis, with special reference to education. 1 ed. Chicago: 1964.

CABRAL, A.; SILVA, C. L. M.; e SILVA. L. F. L. Teoria do Capital Humano, Educação, Desenvolvimento Econômico e suas Implicações na Formação de Professores. Revista Principia. João Pessoa: n.32, 2016. Disponível em:< https://periodicos.ifpb.edu.br/index.php/principia/article/viewFile/1070/575>. Acesso em 16 de maio de 2020.

COSTA, L. S. O Cooperativismo: Uma Reflexão Teórica. Ciências Sociais em Perspectivas, v.6, n.11, p.55-64, 2007. Disponível em: http://saber.unioeste.br/index.php/ccsaemperspectiva/article/view/1500. Acesso em: $28 \mathrm{de}$ agosto de 2021.

CRESWELL, J. W. Projeto de Pesquisa: Método qualitativo, quantitativo e misto: 2 . ed. Porto Alegre: Artmed, 2007.

FACHIN, O. Fundamentos de Metodologia. 5, ed. São Paulo: Saraiva, 2006.

FERREIRA, P. R. SOUSA, D. N. O Campo da Educação Cooperativista e sua Relação com o Serviço Nacional de Aprendizagem do Cooperativismo. Rev. Interações. Campo Grande: v.19, n4, p.773-787, out/dez. 2018. Disponível em: https://www.scielo.br/j/inter/a/XjMrxbm6HjGWpSvJbPtJpkB/?format=pdf\&lang=pt. Acesso em: 29 de agosto de 2021. 
GIL, Antônio. Carlos. Métodos e Técnicas de Pesquisa Social. 6. ed. São Paulo: Atlas, 2008.

IBGE - INSTITUTO BRASILEIRO DE GEOGRAFIA E ESTATÍSTICA. Cidades e Estados, 2021.

LEOPOLDINO, C. J. Elementos Conceituais e Históricos do Cooperativismo. Rev. Ciências Sociais Aplicadas. v.11, n.20, p.141-156. 2011. Disponível em: https://www.bibliotecaagptea.org.br/administracao/cooperativismo/artigos/ELEMENTOS\% 20CONCEITUAIS\%20E\%20HISTORICOS\%20DO\%20COOPERATIVISMO.pdf. Acesso em: 29 de agosto de 2021.

LOURENÇO, T. M. S. P. A Importância da Formação Profissional enquanto Investimento em Capital Humano. 2015. 59 f. Dissertação (Mestrado em Economia) Faculdade de Economia, Universidade de Coimbra, Portugal, 2015.

MARCHIORO, C. D. PONTES, S. R. S. e SILVA, L. Formação Profissional para o Cooperativismo: Percepções e Expectativas dos Alunos do Curso Técnico Integrado ao Ensino Médio no Instituto Federal do Paraná-Campus Capanema. In: I Seminário Internacional de Pós Graduação em Desenvolvimento Rural Sustentável, 22,. 2017. Paraná. Anais Eletrônicos... Paraná: 2017, p.1-14. Disponível em: https://www.researchgate.net/publication/330857698_FORMACAO_PROFISSIONAL_PA RA_O_COOPERATIVISMO_PERCEPCOES_E_EXPECTATIVAS_DOS_ALUNOS_DO _CURSO_TECNICO_INTEGRADO_AO_ENSINO_MEDIO_NO_INSTITUTO_FEDER AL_DO_PARANA-CAMPUS_CAPANEMA. Acesso em: 29 de agosto de 2021.

MINCER, Jacob. Investment in human capital and personal income distribution. Journal of Political Economy, v. LXVI, n. 4, p. 281-302, 1958.

NAMORADO, R. Dicionário das Crises e das Alternativas. Centro de Estudos Sociais. 2012. Disponível em: https://estudogeral.uc.pt/bitstream/10316/90874/1/Cooperativismo.pdf. Acesso em: 29 de agosto de 2021.

NUNES, E. M.; TÔRRES, F. L.; SILVA, M. R. F.; SA, V. C., \& GODEIRO, K. F. (2015) Dinamização Econômica e Agricultura Familiar: limites e desafios do apoio a Projetos de Infraestrutura (Proinf) em territórios rurais do Nordeste. Revista de Economia e Sociologia Rural [impresso], v. 53, p. 529-554.

NUNES, E. M.; GONDIM, M. F. R.; SILVA, M. R. F. Identidade e reestruturação produtiva nos Territórios Açu-Mossoró e Sertão do Apodi, no Rio Grande do Norte. Estudos Sociedade e Agricultura, v.27, n,1 p.137-166, 2019.

NUNES, E. M., CRUZ, M. S. e SILVA, V. M. (2020). Assistência Técnica e Extensão Rural (ATER) no Território Rural Sertão Central Cabugi e Litoral Norte (RN): o desafio da adequação sócio-técnica. Revista Extensão Rural, v. 27, p. 40-64. 
NUNES, E. M.; SILVA, V. M.; SÁ, V. C. Assistência Técnica e Extensão Rural (ATER): formação e conhecimentos para a agricultura familiar do Rio Grande do Norte. Redes (St. Cruz Sul, Online), Santa Cruz do Sul, v. 25, n. 2, p. 857-881, maio 2020. ISSN 1982-6745. Disponível em: https://online.unisc.br/seer/index.php/redes/article/view/14174 Acesso em: 22 maio 2020. doi: https://doi.org/10.17058/redes.v25i2.14174

PLOEG, J. D. van der. (2018). The new pensantries: rural development in times of globalization. 2. ed. London: Earthscan; Sterling VA.

SALES, J. E. Cooperativismo: Origens e Evolução. Revista Brasileira de Gestão e Engenharia. n.1, v.3, p.23-34, jan-jun, 2010. Disponível em: https://www.bibliotecaagptea.org.br/administracao/cooperativismo/artigos/COOPERATIVI SMO\%20ORIGENS\%20E\%20EVOLUCAO.pdf. Acesso em: 28 de agosto de 2021.

SCHULTZ, T. W. O Capital Humano: 2. ed. Rio de Janeiro: Zahar Editores, 1973.

SESCOOP. Diretriz de Atuação Sescoop. Brasília: SESCOOP, 2018.

SESCOOP. Quem Somos. Serviço Nacional de Aprendizagem do Cooperativismo. 2020. Disponível em:< http://sescooprn.coop.br/>. Acesso em: 15 de jun. de 2020. 